\title{
Flexibility Analysis of Inventory Cost Model with Ergonomics
}

\author{
S. KORKULU ${ }^{1}$, K. BONA ${ }^{2}$ \\ 1Budapest University of Technology and Economics, Faculty of Transport Engineering, Department of Material \\ Handling and Logistics Systems, sezen.korkulu@logisztika.bme.hu \\ ${ }^{2}$ Budapest University of Technology and Economics, Faculty of Transport Engineering, Department of Material \\ Handling and Logistics Systems, krisztian.bona@logisztika.bme.hu
}

Abstract. The economic and environmental sustainability issues in supply chain management have integrated by many researchers in the past decades. The ergonomics as a social aspect of sustainability had received a little attention by researchers. Therefore, the aim of the paper is analyzing the flexibility of developed inventory cost model with relaxation allowance and endurance time as a social aspect of sustainability. The effects of distance, unit weight of item and total number of items on relaxation allowance, the total cost of logistics operation and the EOQ model were investigated. The analyzed mathematical model was a single operator-single material model which covered transportation of fixed amount of raw materials from storage plant to production plant by manual material handling with simple cart and picking, storing, pushing and pushing back with empty cart for manual handling of the products. The different parameter values applied for analysis such as total amount of handled items (Q) changes between 500 pcs to 2750 pcs, unit weight of item (w) changes between $0.1 \mathrm{~kg}$ to $1 \mathrm{~kg}$, distance of movement by manual material handling for picking and storing motions (d1) changes between $2 \mathrm{~m}$ to $3 \mathrm{~m}$ and the distance between the storing equipment and the supermarket of the production line for pushing motion (d2) changes between $15 \mathrm{~m}$ to $20 \mathrm{~m}$. The results of the analysis indicated that the longer the distance of movement for all motions leads to decrease in savings of the model compared to EOQ model. The increase in unit weight of item is increase the savings obtained from application of our model and decrease the optimal lot size. There was no specific change on savings or optimal lot size as the total amount of handled item is increase. The compared results indicated that an increase in $d 1$ and $d 2$ lead to an increase in optimal lot size and increase in total cost of the model. Consequently, the analysis has shown that a decrease in lot size would be the better way to improve both ergonomic conditions and total cost of production in any different parameter values. Finally, the analysis of the inventory model with ergonomics were proved that this model is suitable for different industrial practices.

Keywords: Ergonomics, Supply chain management, Endurance time, Rest allowance, Flexibility analysis.

\section{Introduction}

The economic and environmental sustainability issues in supply chain management have integrated by many researchers in the past decades. The ergonomics as a social aspect of sustainability had received a little attention by researchers. Recently, researchers focus on the other supply chain management aspects, such as supply chain performance measures Hassini et al. (2012), supply chain risk 
management Mihalis and Thanos (2016), green supply chain network design integration Rezaee et al. (2017) and sustainability Wolf (2011).

The maximum endurance time has been investigated by a number of researchers. The general model for endurance time was developed by Rohmert (1960) which was a valid for all muscle groups and did not dependent of a worker. The extended endurance time model was developed by Rohmert (1986) for specific muscle groups. The relationship between extend of and holding times for postures and relative force for the static pull and static torque have been investigated by Corlett and Manenica (1980). Rose et al. (2001) have been investigated endurance time, pain and resumption time for fully flexed postures. Their results indicated that endurance times in fully flexed postures differ little from those in more common postures.

This paper aims to analyze the flexibility of the lot sizing model with ergonomics aspects as a social sustainability component. Therefore, the major objectives of this study are: (1) to understand the effects of unit weight of item, total amount of handled item and distances of movement by manual material handling for picking, storing and pushing on the total cost of logistics operation, (2) to investigate the effects of unit weight of item, total amount of handled item and distances of movement by manual material handling for picking, storing and pushing on the lot size.

The next section has been presented the detail of the methodology adopted to carry the entire study. Section 2 has been presented the details of the results of the analysis. Section 3 provided the conclusions of the entire study, including the future scope of analysis for ergonomics aspects in lotsizing research.

\section{Methodology}

\subsection{The AIM methodology}

The AIM tables have been used for calculating the time necessity of material handling systems. It has been used to planning systems with material handling by hand without tools, material handling by hand with tools, electronic pedestrian stackers, fork lift trucks and handling with towing tractor (Barta \& Bona, 2010). We applied the following parameter values for calculating the time needs of different practices>

\begin{tabular}{|c|c|c|c|}
\hline $\begin{array}{c}\text { Hpiup (height of } \\
\text { picking up) }\end{array}$ & $\begin{array}{c}\text { Hpl (height of } \\
\text { placement) }\end{array}$ & $\begin{array}{c}\mathrm{d} 1 \text { (distance of } \\
\text { movement by manual } \\
\text { material handling for } \\
\text { picking and storing) }\end{array}$ & $\begin{array}{c}\mathrm{d} 2 \text { (distance of } \\
\text { movement by manual } \\
\text { material handling for } \\
\text { pushing) }\end{array}$ \\
\hline $1.2 \mathrm{~m}$ & $0.2 \mathrm{~m}$ & $2 \mathrm{~m}$ & $15 \mathrm{~m}$ \\
\hline $1.2 \mathrm{~m}$ & $0.2 \mathrm{~m}$ & $3 \mathrm{~m}$ & $30 \mathrm{~m}$ \\
\hline
\end{tabular}

Table 1. The AIM time needs calculation parameters.

\subsection{The mathematical model}

In the literature, there can be found very few lot sizing and inventory cost model with ergonomics. Battini et al. (2017) have been developed a mathematical model which investigates ergonomic lot size 
for picking and storing motions. They integrated Price (1990) rest allowance formulation to the lot sizing model. We extended and developed inventory cost model which integrates the Rohmert (1973) maximum endurance time and relaxation allowance formulations as ergonomics aspects for picking, storing and pushing motions in a single material-single operator model. The analysed total cost function with ergonomics as follows:

$$
\begin{aligned}
& C(q)=\left(t_{a} \times q \times\left\lceil\frac{Q}{q}\right\rceil\right) \times \frac{c_{h}}{2}+\left[t_{p}(q)+t_{s}(q)+t_{p u s h}(q)+t_{p u s h b}+\left(T_{R_{t_{p}}}(q)+T_{R_{t_{s}}}(q)+T_{R_{t_{p u s h b}}}+T_{R_{t_{p u s h}}}(q)\right)\right] \times \\
& c_{w} \times\left\lceil\frac{Q}{q}\right\rceil
\end{aligned}
$$

According to Rohmert (1973), $T_{R_{t_{p}}}(q), T_{R_{t_{s}}}(q), T_{R_{t_{p u s h b}}}, T_{R_{t_{p u s h}}}(q)$ calculated as:

$T_{R}(q)=1800 \times\left(t /-1.5+\frac{2.1}{f M V C}-\frac{0.6}{f M V C^{2}}+\frac{0.1}{f M V C^{3}}\right)^{1.4} \times(f M V C-0.15)^{0.5}$

Where $C(q)$ is the total cost of the production line supply (\$), $t_{a}$ is the availability time of the stock on the production line $(s),\left[\frac{Q}{q}\right\rceil$ is the number of cycle needed for handling total $(\mathrm{Q})$ amount of items, $c_{h}$ is the inventory holding cost, $t_{p}(q)$ is unit picking time from the storage equipment to the cart $(\mathrm{s}), t_{s}(q)$ is unit storing time from the cart to the supermarket of the production line $(s), t_{p u s h}(q)$ is the cart pushing time to supermarket (s), $t_{p u s h b}$ is the cart pushing back time to storage $(\mathrm{s}), T_{R_{t p}}(q)$ is rest time needed for picking (s), $T_{R_{t_{s}}}(q)$ is rest time needed for storing (s), $T_{R_{t_{p u s h b}}}$ is rest time needed for pushing back (s), $T_{R_{t} \text { push }}(q)$ is rest time needed for pushing $(\mathrm{s}), c_{w}$ is unit worker wage $(\$ / \mathrm{h}), \mathrm{t}$ is a

\begin{tabular}{|c|c|c|c|}
\hline$Q$ (pcs) & w (kg) & $\mathrm{d} 1(\mathrm{~m})$ & $\mathrm{d} 2(\mathrm{~m})$ \\
\hline 500 & 0.1 & 2 & 15 \\
\hline 750 & 0.15 & 3 & 20 \\
\hline 1000 & 0.2 & & \\
\hline 1250 & 0.25 & & \\
\hline 1500 & 0.3 & & \\
\hline 1750 & 0.35 & & \\
\hline 2000 & 0.4 & & \\
\hline 2250 & 0.45 & & \\
\hline 2500 & 0.5 & & \\
\hline \multirow[t]{10}{*}{2750} & 0.55 & & \\
\hline & 0.6 & & \\
\hline & 0.65 & & \\
\hline & 0.7 & & \\
\hline & 0.75 & & \\
\hline & 0.8 & & \\
\hline & 0.85 & & \\
\hline & 0.9 & & \\
\hline & 0.95 & & \\
\hline & 1 & & \\
\hline
\end{tabular}
contraction duration (s) and $f M V C$ is the relative force.

Table 2. Parameter values of analysis. 
As shown in Table 2, we applied different unit weight of item, total amount of handled items and distance of movement by manual material handling (picking, storing and pushing) for investigating the cost model in some realistic cases.

\section{Results}

We applied and compared the results of different parameter values in our model. As shown in Figure 1 and Figure 2, the savings are calculated according to the EOQ model optimal lot size values for each $Q$ $w, d 1$ and $d 2$. The increase in unit weight of item is increase the savings obtained from application of our model. The decrease in the savings as the total amount of handled item is increase.

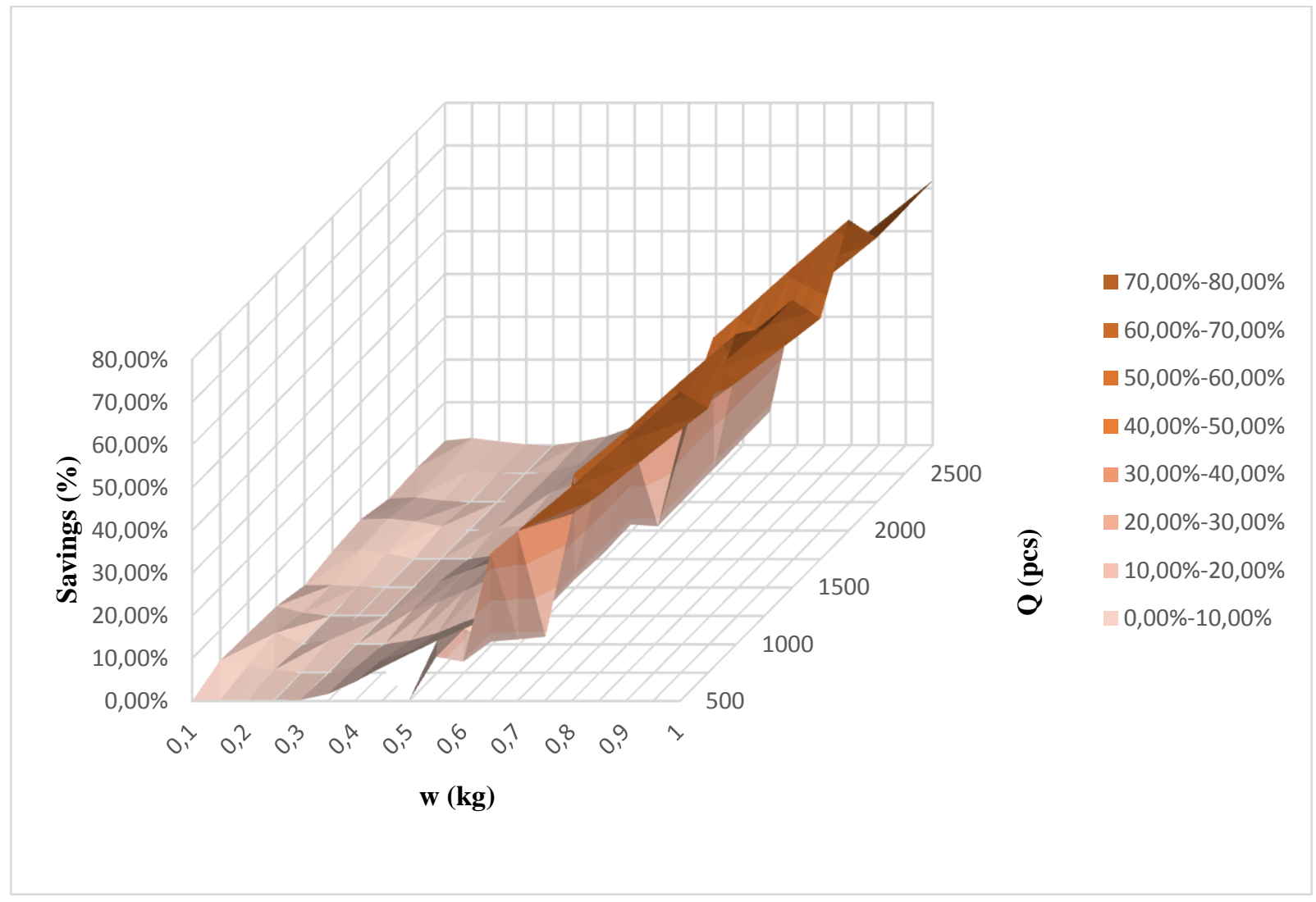

Figure 1. Savings of the model for different unit weight of item and total amount of handled item (d1=3 $\mathrm{m}$ and $d 2=20 \mathrm{~m}$ )

The comparison of the results of the Figure 1 and Figure 2 indicated that the longer the distance of movement for all motions leads to decrease in savings of the model compared to EOQ model. 
International Journal of Engineering and Management Sciences (IJEMS) Vol. 4. (2019). No. 1

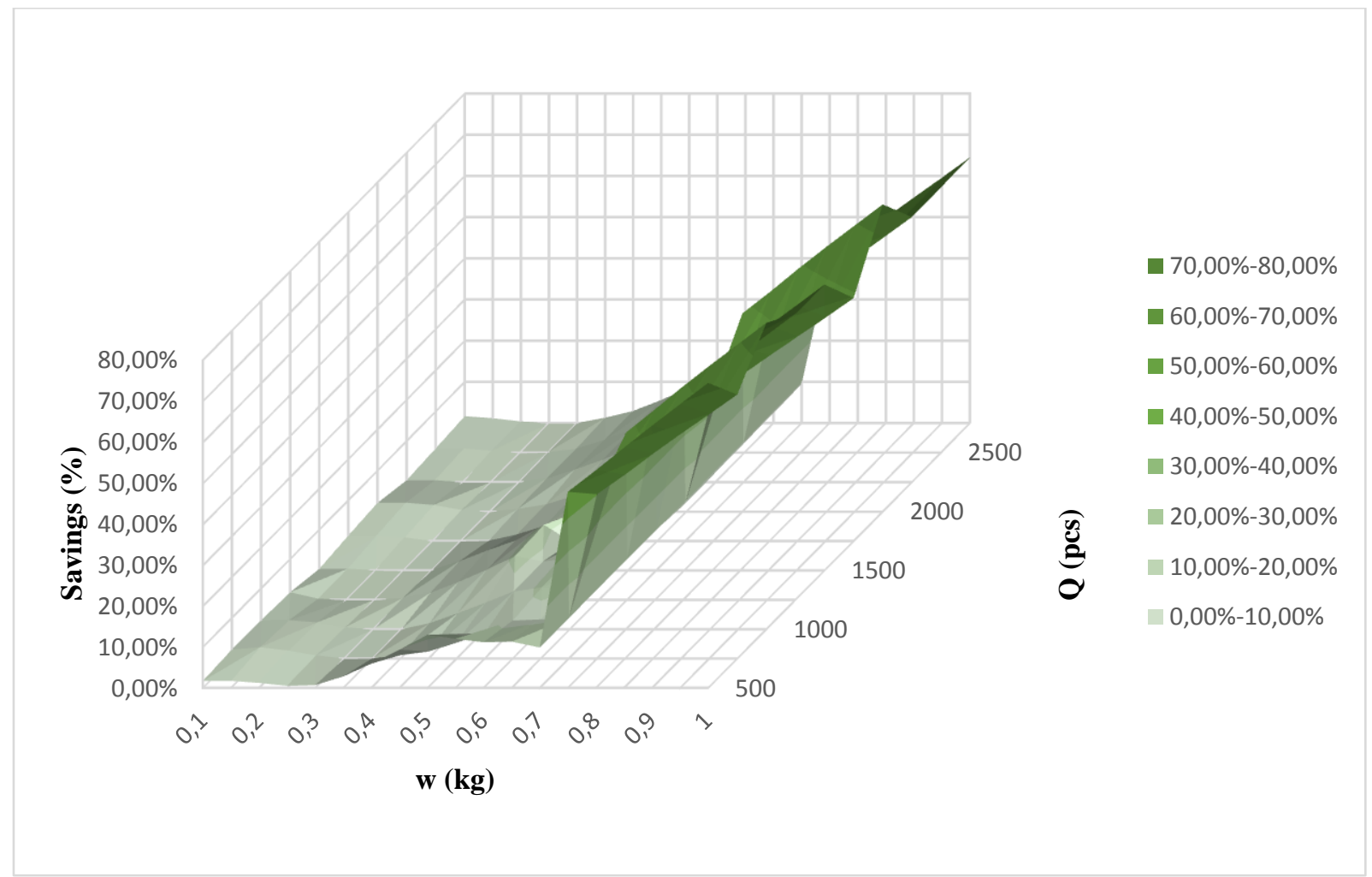

Figure 2. Savings of the model for different unit weight of item and total amount of handled item (d1=2 $\mathrm{m}$ and $d 2=15 \mathrm{~m}$ )

The optimal lot size for different $\mathrm{Q}, \mathrm{w}$ and distance of movement were given in Figure 3 and Figure 4.

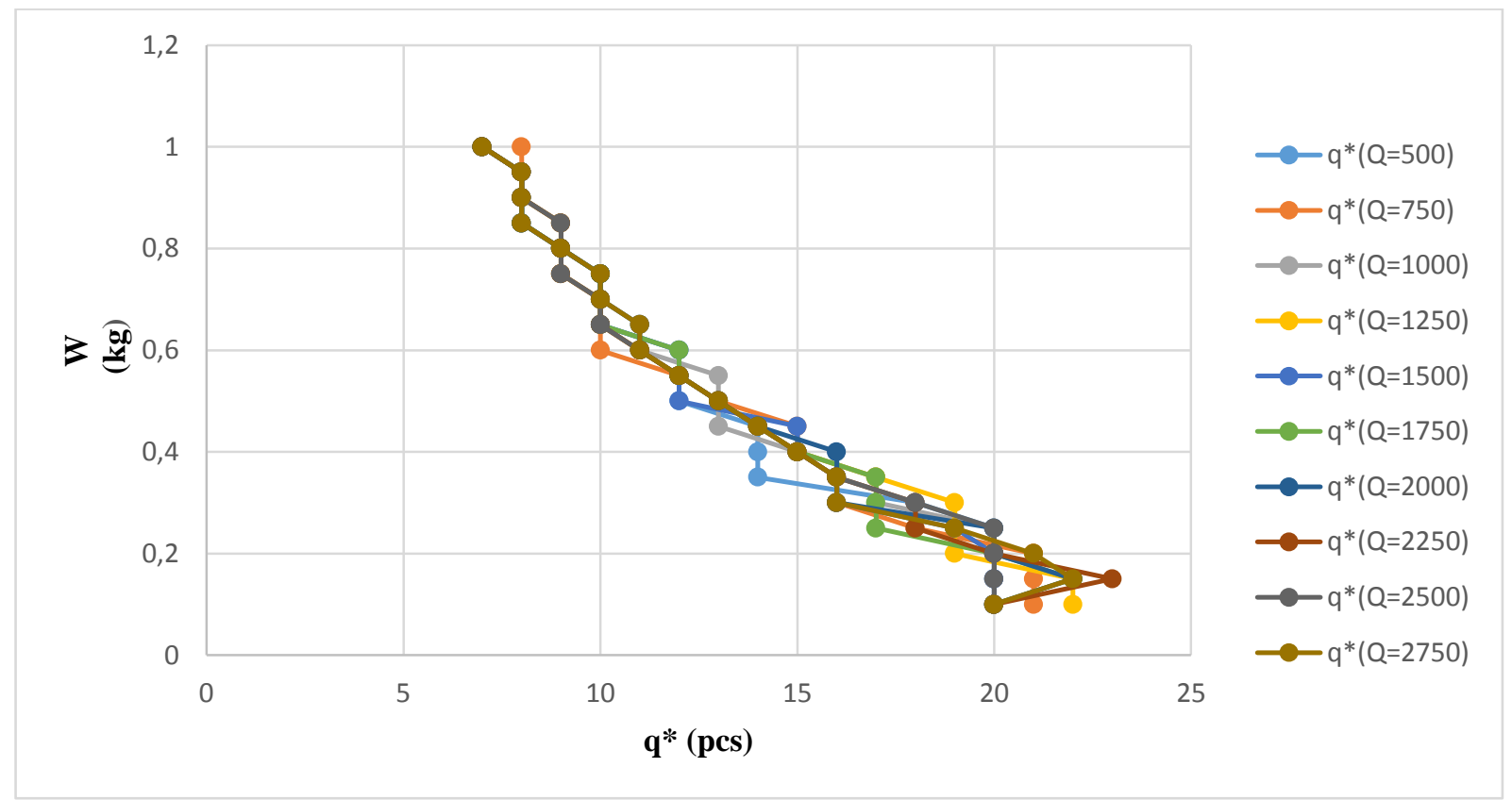

Figure 3. Optimal lot size for different total amount of handled item and unit weight of item ( $d 1=3 \mathrm{~m}$ and d2=20 $\mathrm{m}$ )

As can be seen in Figure 3 and Figure 4, increase in unit item weight decrease the lot size and there is no big difference in lot size as the total amount of handled item changes. 
International Journal of Engineering and Management Sciences (IJEMS) Vol. 4. (2019). No. 1

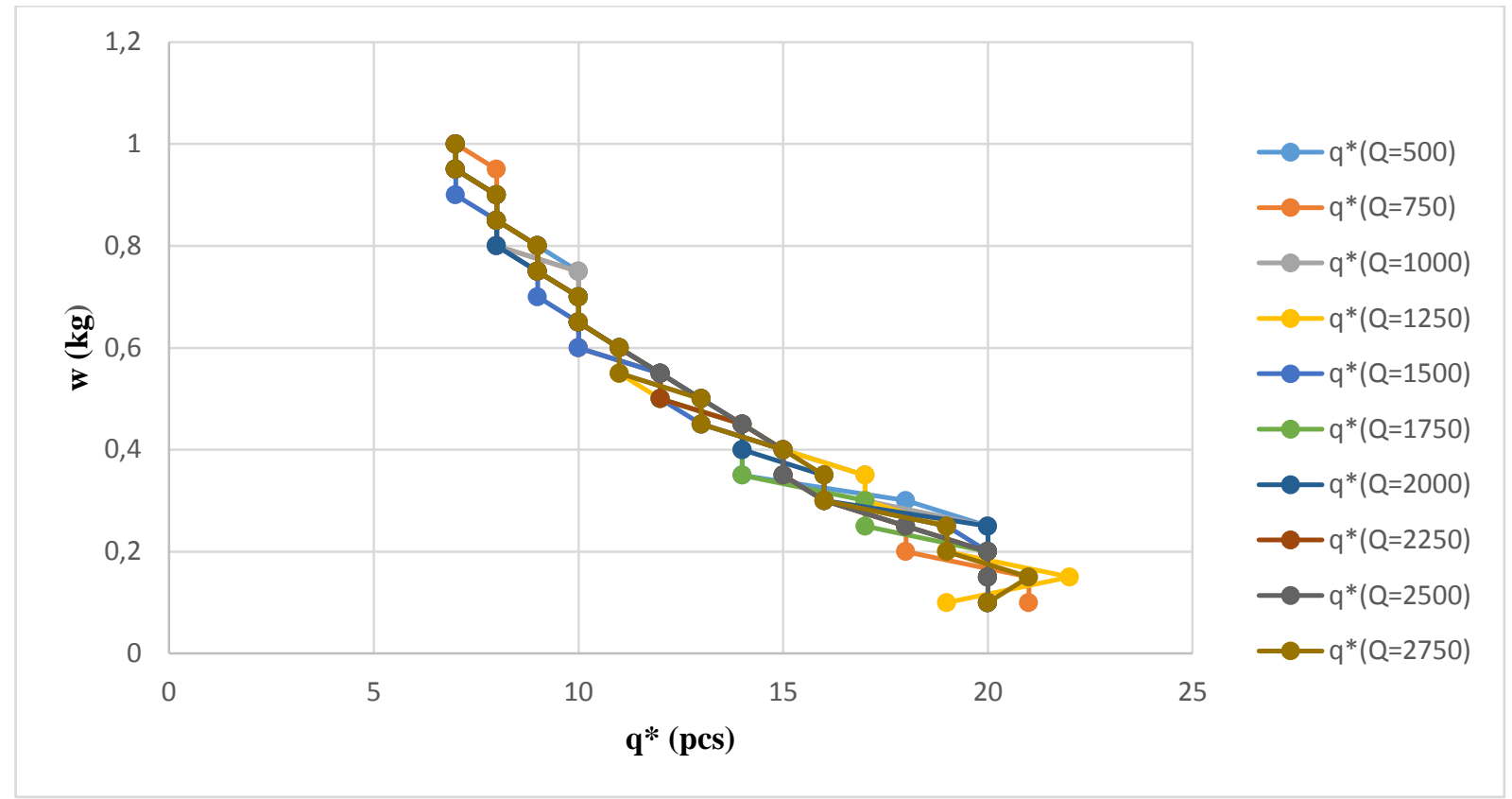

Figure 4. Optimal lot size for different total amount of handled item and unit weight of item ( $d 1=2 \mathrm{~m}$ and $d 2=15 \mathrm{~m}$ )

The compared results indicated that an increase in $\mathrm{d} 1$ and $\mathrm{d} 2$ lead to an increase in optimal lot size and increase in total cost of the model.

The total cost of the operation of our model $\left(C^{*}\right)$ and EOQ (C(EOQ)) for different unit item weight, total amount handled items and distance of movement were given in Figure 5 and Figure 6.

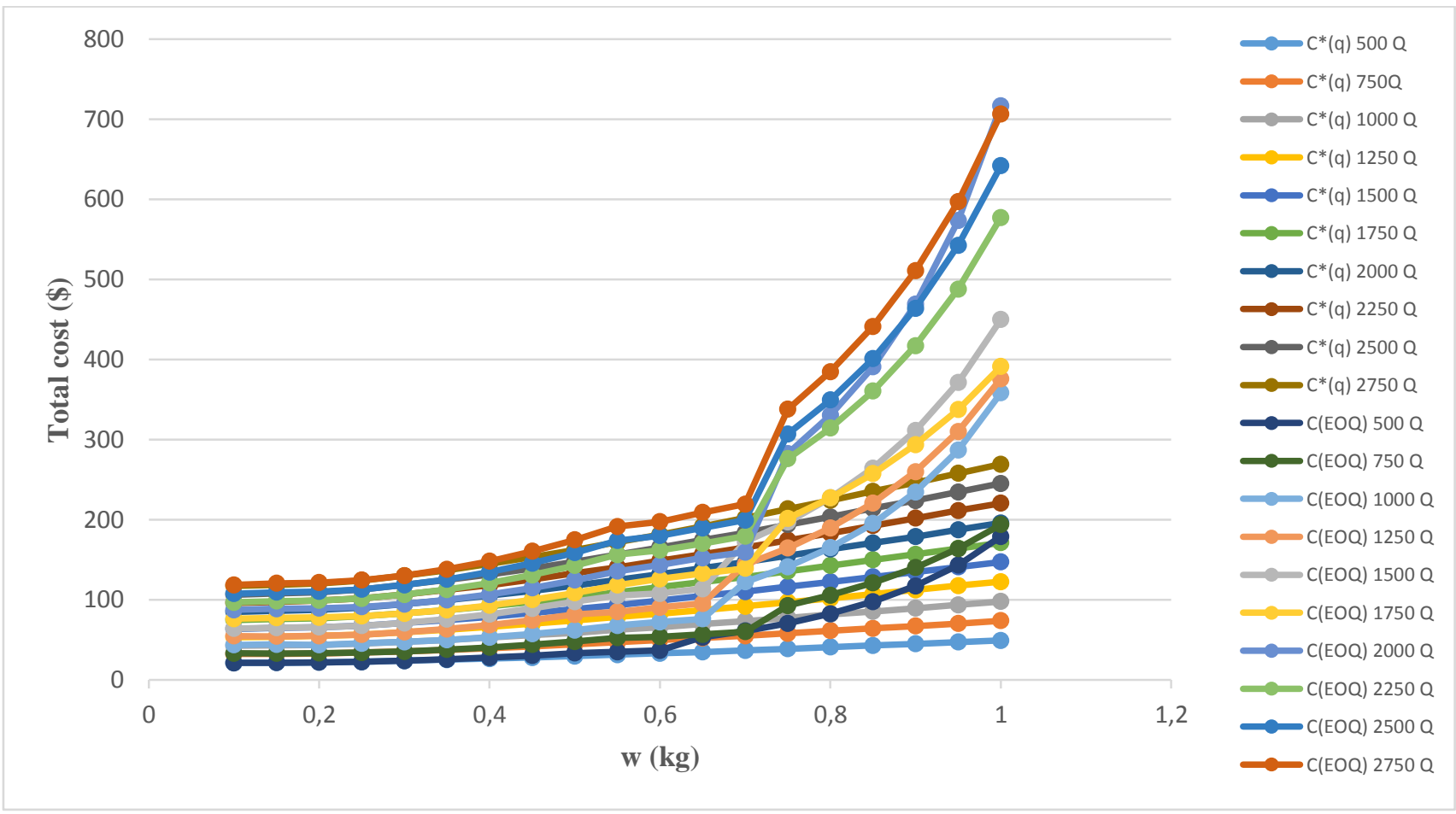

Figure 5. Total cost of the operation for different unit item weight and total amount handled items ( $d 1=3 \mathrm{~m}$ and $d 2=30 \mathrm{~m}$ ) 
We calculated the total costs of the operation for optimal lot sizes of both model for different values. As results indicate in both figure, the increase in unit item weight increase the total cost of operation. Especially, EOQ model has higher total cost of operation as it has a higher optimal lot size value for each value. Therefore, the rest time is higher for EOQ model and it leads to higher rest time cost for reducing the ergonomic risks.

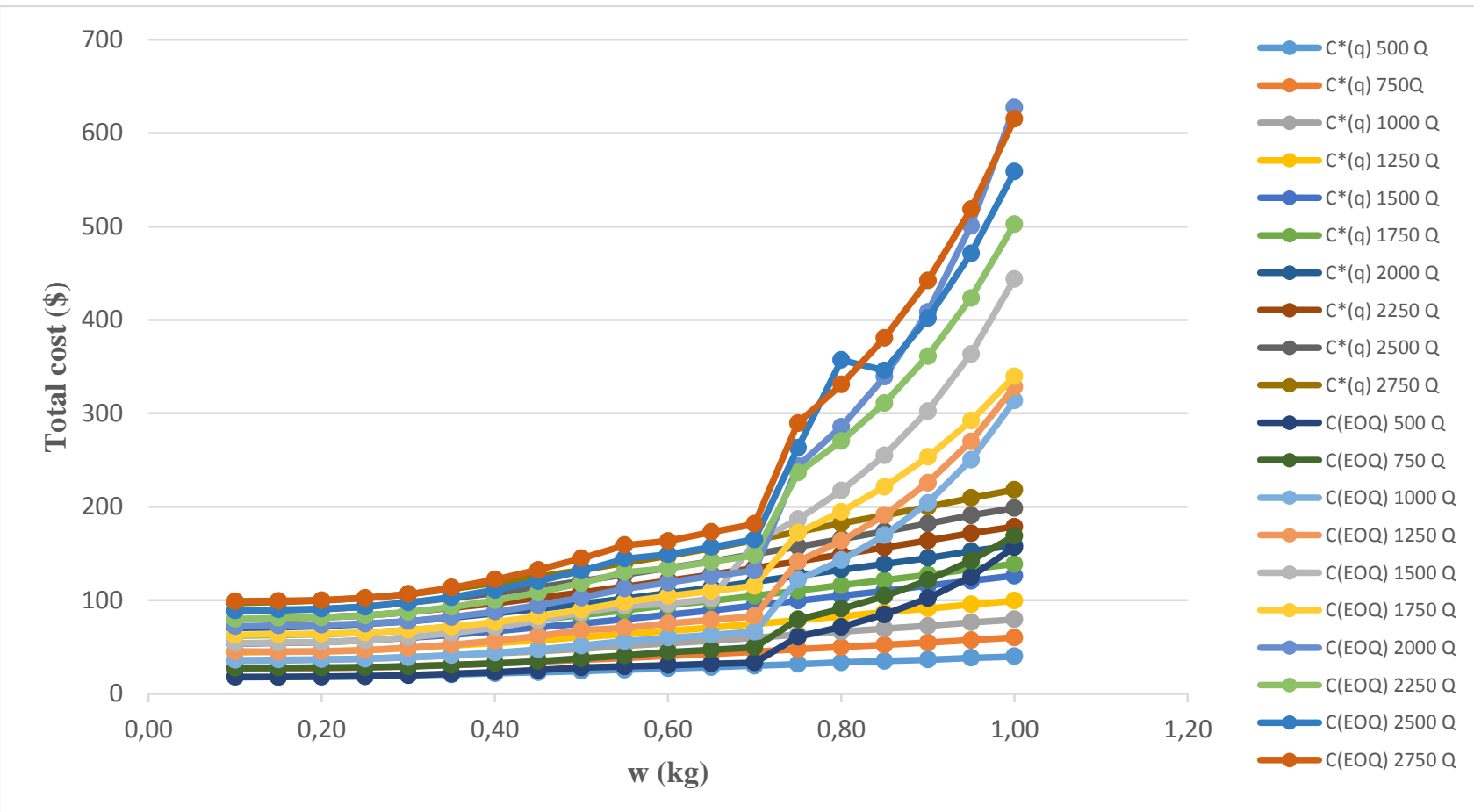

Figure 6. Total cost of the operation for different unit item weight and total amount handled items (d1=2 $\mathrm{m}$ and $d 2=15 \mathrm{~m}$ )

The compared results indicated that an increase in $\mathrm{d} 1$ and $\mathrm{d} 2$ lead to an increase the total cost of operation of the both our model and EOQ model.

Consequently, the analysis has shown that a decrease in lot-size would be the better way to improve both ergonomic conditions and total cost of production in any different parameter values.

\section{Conclusion and further research}

Work-related musculoskeletal disorders are a group of painful disorders of muscles, tendons, and nerves. Work patterns which are frequent and repetitive or patterns with awkward postures, heavy lifting or physical strain can cause these conditions. The ergonomic risks and work related musculoskeletal disorders such as sprains, strains, tears, back pain and carpal tunnel syndrome are crucial problem in the World. They can be a major cause of loss of productivity in the workplace. Therefore, to improve ergonomic conditions in workplaces, the inventory cost model with ergonomic aspects analysed in this paper. The analysis was proved that the inventory cost model with 
ergonomics is suitable for different industrial practices. Furthermore, it can improve both productivity and ergonomic conditions.

The investigation of other ergonomic motions such as pulling, bending could be good extension of this study. Furthermore, semi-automated production line model where repetitive motion and force of movement could utilise work related musculoskeletal disorders would be good extension of this study.

\section{References}

[1] Z. Barta - K. Bona K. (2010) Development of AIM method planning of inbound material handling processess. Acta Technica Jaurinensis Series Logistica. 3(3) pp. 285-299.

[2] D. Battinia - H. C. Glock - E. H. Grosse - A. Persona - F. Sgarbossa (2017) Ergo-lot-sizing: An approach to integrate ergonomic and economic objectives in manual materials handling. International Journal of Production Economics. 185 pp. 230-239.

[3] E. N. Corlett - I. Manenica (1980) The effects and measurement of working postures. Applied Ergonomics. 11 (10) pp. 7-16.

[4] E. Hassini - C. Surti - C. Searcy (2012) A literature review and a case study of sustainable supply chains with a focus on metrics. International Journal of Production Economics. 140 (1) pp. 69-82.

[5] G. Mihalis - P. Thanos (2016) Supply chain sustainability: A risk management approach. International Journal of Production Economics. 171 pp. 455-470.

[6] A. D. Price, A. D. (1990) Calculating relaxation allowances for construction operatives-Part 1: Metabolic cost. Applied ergonomics. 21(4) pp. 311-317.

[7] A. Rezaee - F. Dehghanian - B. Fahimnia - B. Beamon 2017) Green supply chain network design with stochastic demand and carbon price. Annals of Operations Research. 250(2) pp. 463-485.

[8] W. Rohmert (1960) Ermittlung von Erholungspausen für Statische Arbeit des Menschen. Internationale Zetischrift fur Angewandte Physiologie Einschliesslich Arbeitphysiologie. 18 pp. 123-164.

[9] W. Rohmert (1973b) Problems in determining rest allowances. Part 2: determining rest allowances in different tasks. Applied Ergonomics. 4(3) pp. 158-162.

[10] W. Rohmert - M. Wangenheim - J. Mainzer - P. Zipp - W. Lesser (1986) A study stressing the need for a static postural force model for work analysis. Ergonomics. 29(10) pp. 1235-1249.

[11] L. Rose - R. Ortengren - M. Ericsson (2001) Endurance, pain in fully flexed postures. Applied Ergonomics. 32 pp. 501-508.

[12] J. Wolf (2011) Sustainable supply chain management integration: a qualitative analysis of the German manufacturing industry. Journal of Business Ethics 102 (2) pp. 221-235. 